\title{
Frontiers in pruritus research: scratching the brain for more effective itch therapy
}

\author{
Ralf Paus, ${ }^{1}$ Martin Schmelz, ${ }^{2}$ Tamás Bíró, ${ }^{3}$ and Martin Steinhoff ${ }^{4}$
}

\begin{abstract}
${ }^{1}$ Department of Dermatology and Allergy, University of Lübeck, Lubeck, Germany. ${ }^{2}$ Department of Anesthesiology and Critical Care Medicine, Faculty of Clinical Medicine Mannheim, University of Heidelberg, Mannheim, Germany. ${ }^{3}$ Department of Physiology, University of Debrecen, Medical and Health Science Center, Research Center for Molecular Medicine, Debrecen, Hungary. ${ }^{4}$ Department of Dermatology, IZKF Münster, Ludwig Boltzmann-Institute for Immunobiology of the Skin, University Hospital Münster, Munster, Germany.
\end{abstract}

This Review highlights selected frontiers in pruritus research and focuses on recently attained insights into the neurophysiological, neuroimmunological, and neuroendocrine mechanisms underlying skin-derived itch (pruritogenic pruritus), which may affect future antipruritic strategies. Special attention is paid to newly identified itch-specific neuronal pathways in the spinothalamic tract that are distinct from pain pathways and to CNS regions that process peripheral pruritogenic stimuli. In addition, the relation between itch and pain is discussed, with emphasis on how the intimate contacts between these closely related yet distinct sensory phenomena may be exploited therapeutically. Furthermore, newly identified or unduly neglected intracutaneous itch mediators (e.g., endovanilloids, proteases, cannabinoids, opioids, neurotrophins, and cytokines) and relevant receptors (e.g., vanilloid receptor channels and proteinase-activated, cannabinoid, opioid, cytokine, and new histamine receptors) are discussed. In summarizing promising new avenues for managing itch more effectively, we advocate therapeutic approaches that strive for the combination of peripherally active antiinflammatory agents with drugs that counteract chronic central itch sensitization.

\section{The study of pruritus in a nutshell}

Itching (pruritus) is perhaps the most common symptom associated with numerous skin diseases and can be a lead symptom of extracutaneous disease (e.g., malignancy, infection, and metabolic disorders) (1, S1). However, despite approximately a century of pruritus research $(2, S 2, S 3)$, there is no generally accepted therapy for the treatment of itch, and many mysteries, misconceptions, and controversies still haunt this rather neglected, yet clinically important and scientifically fascinating, niche in the life sciences $(3,4,5)$.

\section{It is the brain that itches, not the skin}

Pruritus causes the desire to scratch the skin and is experienced as a sensation arising in the skin. However, like all other skin sensations, itch, strictly speaking, is an extracutaneous event - a product of CNS activities. The intense itch we feel after an insect bite, in a patch of atopic eczema, during an episode of food-induced urticaria, or in association with diabetes, uremia, or scabies mite infection (S1) represents a neuronal projection of a centrally formed sensation into defined regions of the integument (localized pruritus) or into large territories of our body surface (generalized pruritus).

Interestingly, our individual reception of and emotional response to itch strongly depends on its exact quality: while a tickling sensation usually is experienced as pleasurable, persistent itch is an annoying or even torturous sensation (S4). While one is tempted to interpret this as indicating a distinct molecular and/or structural basis of these different itch qualities, it has proven excruciatingly difficult to identify their molecular, structural, and neurophysiological differences (ref. 1; see below).

Nonstandard abbreviations used: $\mathrm{ACh}$, acetylcholine; $\mathrm{CB}$, cannabinoid receptor; CGRP, calcitonin gene-related peptide; NGF, nerve growth factor; PAR, proteinaseactivated receptor; SP, substance P; TRP, transient receptor potential; TRPV, TRP vanilloid-type.

Conflict of interest: The authors have declared that no conflict of interest exists. Citation for this article: J. Clin. Invest. 116:1174-1185 (2006). doi:10.1172/JCI28553.
As pruritus can arise from localized or systemic, peripheral or central stimuli, it is useful to differentiate between its different types. One recent classification system suggests distinctions be made among neurogenic (arising from neurophysiological dysfunction, e.g., due to cholestasis or psychotropic medication), neuropathic (due to a primary neurological disorder), psychiatric (e.g., parasitophobia), and pruritogenic pruritus (arising from skin diseases) $(3,6)$. This Review discusses only the latter, most frequent type of pruritus, which requires the involvement and activity of cutaneous sensory neurons that transmit the "itchy" signals via dorsal root ganglia and the spinal cord to the CNS.

Current concepts of itch pathways underlying pruritogenic pruritus and of CNS regions involved in itch processing are summarized in Figure 1. More plainly speaking, when one senses the difficult-to-control desire to fight itching by self-inflicted painful stimuli, the impression that one's skin itches is nothing but a sensory illusion created by the brain. Thus the CNS-controlled, itch-alleviating motoric activity that unfolds in response to pruritus directly "talks back" to our CNS, almost as if we were scratching the brain itself.

\section{Scratching highlights the close relation of pain and itch}

Both pain and itch can be reduced by soft rubbing, which activates fast-conducting, low-threshold nerve fibers (7). However, the most characteristic response to itching is the scratch reflex: a more or less voluntary, often subconscious motoric activity to counteract the itch by slightly painful stimuli. This itch reduction is based on a spinal antagonism between pain- and itch-processing neurons (8). This illustrates a therapeutically exploitable, key concept in contemporary pruritus research: itch appears to be under tonic inhibitory control of pain-related signals $(1,4,5,8,9)$. Indeed, itch and pain share the use of many neurophysiological tools and processing centers and induce similar autonomous skin reactions. Also, chronic pain and central sensitization to itch appear to be neurophysiologically closely related phenomena (4). 


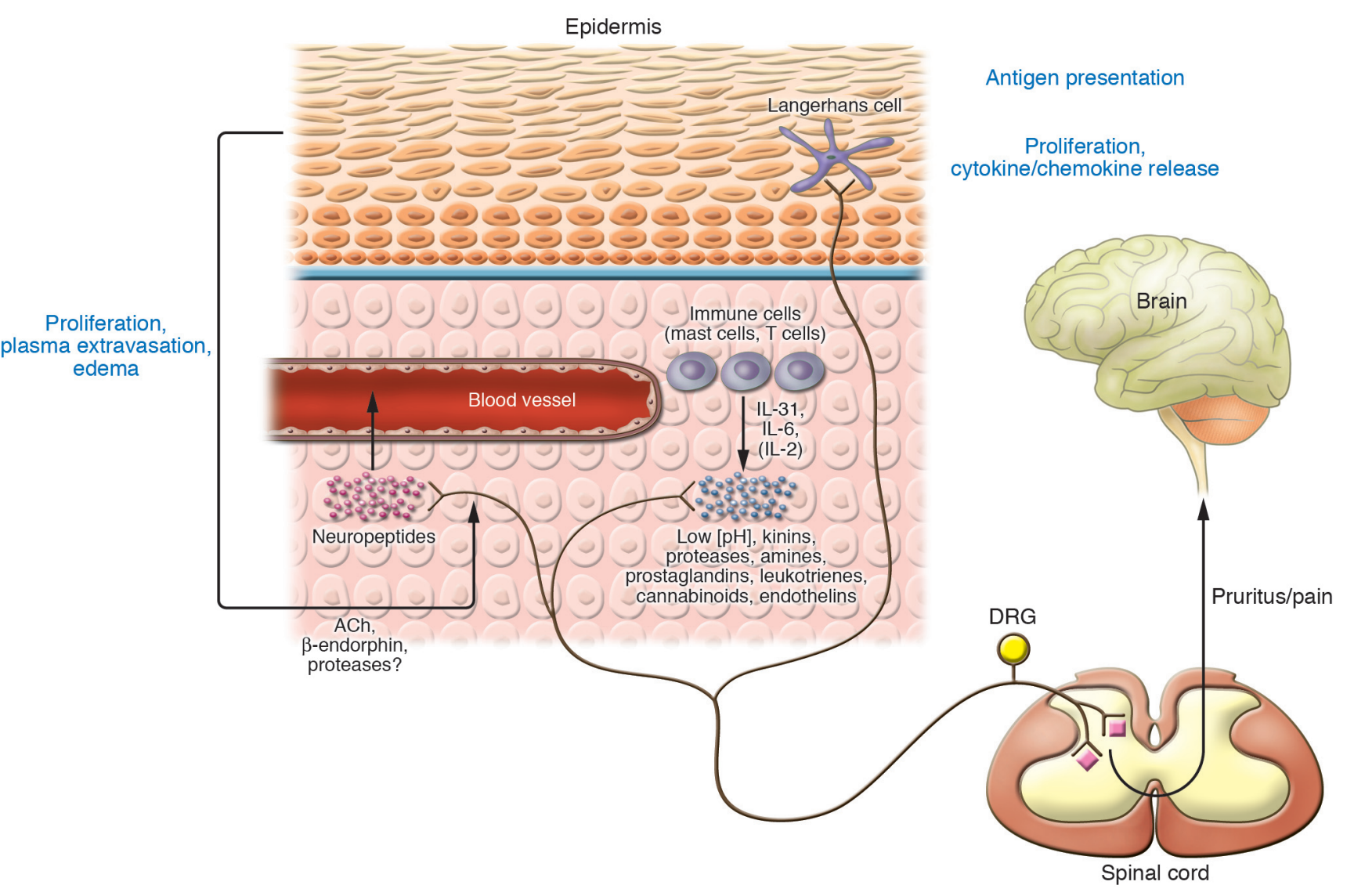

Figure 1

Table 2 and neurophysiological pathways activated during pruritus (pruritogenic itch). Exogenous or endogenous mediators stimulate specific subtypes of peripheral nerve endings of primary afferent neurons (pruriceptors). High-affinity receptors for pruritogenic mediators transmit the stimulus via intracellular signaling from the periphery to the dorsal root ganglia (DRG) and the spinal cord. Within the spinal cord, itch signals can be modulated (see It is the brain that itches, not the skin). From lamina I, a specific area within the dorsal horn of the spinal cord, the signal is transmitted to the CNS after crossing to the contralateral side (see Figure 3). Activation of specific areas in the CNS results in the perception of itch, leading to discomfort and a scratch response. Additionally, the associated peripheral axon reflex may lead to the release of mast cell-stimulating neuropeptides (e.g., SP), thereby amplifying pruritus via release of histamine, tryptase, and TNF- $\alpha$, for example (see Table 1). This figure does not consider the interaction between pain and itch fibers on the spinal cord level (see The enigmatic neurophysiology of itch is becoming increasingly understood). Figure modified with permission from The Journal of Investigative Dermatology (5).

\section{Itch and pain serve different purposes}

Yet itch is clearly distinct from pain with respect to the subjective sensation, the inducing stimuli, and the reflex patterns. In contrast to pain-related withdrawal reflexes, itching stimuli provoke the characteristic scratching reflex. This close connection suggests that the neuronal apparatus for itch has developed as a nocifensive system for removal of irritating objects and agents assaulting the skin and thereby the body's integrity (e.g., parasites, insects, sharp objects, irritants, and allergens). While the withdrawal reflex is an adequate response to external noxious stimuli, scratching makes good sense for noxious agents that have successfully passed the epidermal barrier and have already invaded the skin. Here, withdrawal would be useless. Instead, localizing the injured site by scratching and subjecting it to closer examination in order to detect any exogenous danger is required. Thus having skin capable of inducing the symptom of itch may have afforded a substantial selective advantage during evolution.

\section{The sensation of itch and nociception are distinct entities}

Results from early psychophysical studies on itch and pain "spots" (S5) invited the interpretation that itch is a kind of low-intensity pain. However, we now know that the sensation of itch and nociception cannot be equated with each other. In fact, the once-popular theories that itch is based on a specific pattern of action potentials running through pain pathways or that itch results from the combination of other primary sensory signals have now fallen out of favor $(3,10)$. Likewise the confirmation of the long-denied existence of central itch-specific neuronal pathways in the human and feline systems supports the concept that the sensation of itch and nociception represent distinct sensory systems $(9,11)$. Nevertheless, it remains perhaps the most central, and as yet unmet, challenge of neurophysiological pruritus research to fully unravel the biological commonalities and differences between itch and pain. In any case, the systematic, comparative exploration of the mechanisms underlying pain and itch sensations has already proven to be a constant source of innovation and stimulation for investigators who study pruritus. 
Table 1

"The itching army" — selected pruritogens, their sources, and functions

$\begin{array}{lll}\begin{array}{l}\text { Pruritogenic } \\ \text { stimuli }\end{array} & \text { Receptors } & \begin{array}{l}\text { Sources, receptors } \\ \text { expressed by }\end{array} \\ \text { ACh } & \begin{array}{l}\text { Nicotinergic } \\ \text { (nAChR) and }\end{array} & \begin{array}{l}\text { Autonomic cholinergic } \\ \text { nerves, keratinocytes, }\end{array} \\ & \begin{array}{l}\text { muscarinergic } \\ \text { (mAChR) ACh }\end{array} & \begin{array}{l}\text { lymphocytes, } \\ \text { melanocytes, dermal } \\ \text { fibroblasts, ECs }\end{array} \\ & \text { receptors } & \text { Sensory nerve fibers }\end{array}$

$\mathrm{CRH}$ and POMC $\quad \mathrm{CRH}-\mathrm{R} 1$ and $-\mathrm{R} 2$

Cytokines (e.g., IL-1, IL-31) ECs, nerves

Endocannabinoids $\mathrm{CBs}(\mathrm{CB} 1, \mathrm{CB} 2)$

ETs

ET receptors

$$
\left(E T_{A}, E T_{B}\right)
$$

Endovanilloids ${ }^{A} \quad$ Activation of TRPV1. Sensitization of TRPV1 via activation of specific receptors.

Histamine

Histamine

receptors

(H1R-H4R)

Kallikreins, proteases

Partly by PARs, tryptic enzymes mast cells; for CRH-R2, BM mast cells

Nerves, immune cells, keratinocytes, hair follicles

Endothelium, mast cells

TRPV1 expressed on epidermal and hair follicle keratinocytes, Langerhans cells, smooth muscle, and sebocytes

Sensory nerve fibers

Keratinocytes, ECs, mast cells, platelets
Cytokine receptors Leukocytes, keratinocytes,

For CRH-R1, keratinocytes, sensory neurons, mast cells,

$\begin{array}{lll}\text { Kinins } & \begin{array}{l}\text { Bradykinin receptors } \\ \text { (B1R, B2R) }\end{array} & \text { ECs, immunocytes } \\ \text { Leukotriene B4 } & \begin{array}{l}\text { Leukotriene } \\ \text { receptors }\end{array} & \begin{array}{l}\text { Sensory nerve fibers, } \\ \text { keratinocytes }\end{array} \\ \text { NKA and SP } & \begin{array}{l}\text { Tachykinin (NK) } \\ \text { receptors (NKRs) }\end{array} & \text { Sensory nerve fibers } \\ & \end{array}$

NGF, BDNF, NTs

Specific receptors: TrkA (NGF), TrkB (NT-4, BDNF),

Keratinocytes, mast cells, fibroblasts, eosinophils

\section{Comments}

Selected references

Mediates itch in $A D$ patients.

mAChR3 is probably involved in itch.

$(35,111$,

Expression on central terminals; sensitization of nerve endings. Increased pain transmission; prolongation of itch latency following SP injection (inhibitory effect on itching). Involved in itchy skin diseases.

Release of histamine, cytokines, TNF- $\alpha$, VEGF from mast cells. $\mathrm{CRH}$-like immunoreactivity on sensory nerves (rat).

T cells release IL-31 during inflammation and activate monocytes and keratinocytes via the IL-31 receptor (IL-31R). IL-31R is upregulated in AD and prurigo.

Antipruritic in the periphery.

$(10,113$,

Burning itch; degraded by chymase via $\mathrm{ET}_{\mathrm{A}}$ receptor activation.

Short-term TRPV1 activation: pain and itch induction, depletes neuropeptides from sensory neurons. Long-term antipruritic effect of TRPV1 agonists (e.g., capsaicin): suspend interplay between sensory neurons and mast cells. Affects epidermal and hair follicle proliferation, differentiation, apoptosis, and cytokine release. Increased expression in epidermal keratinocytes of prurigo nodularis patients.

In humans, histamine induces itch by stimulating specific sensory fibers, whereas $\mathrm{H} 1$ (and $\mathrm{H} 2$, less so) antagonists reduce itch in numerous clinical trials. In mice, H3 antagonists induce scratching behavior, whereas $\mathrm{H} 1$ and $\mathrm{H} 4$ antagonists effectively suppress pruritus.

Massive itch behavior in mice overexpressing

$(1,11,27$, S23, S24) epidermal kallikrein-7. Potential role of other kallikreins. Chymase degrades pruritic and antipruritic peptides. Tryptase induces inflammation and itch by a neurogenic mechanism via $\mathrm{PAR}_{2}$. Microbial proteases may induce itch and inflammation via $\mathrm{PAR}_{2}$.

Bradykinin induces pain rather than pruritus. B2R antagonists reduce itch.

Leukotriene B4 induces itch and is also involved in the SP- and nociceptin-mediated induction of itch.

NKA: Upregulation of keratinocyte NGF expression. SP: low (physiologically relevant) concentrations: priming of mast cells; release of TNF- $\alpha$, histamine, leukotriene B4, and prostaglandins from mast cells (agents involved in pruritus and burning).

NGF levels enhanced in $A D$; induces tryptase release from mast cells. Inducible by histamine. TrkA enhanced in karatinocytes during inflammation. NT-4 enhanced in $A D$, induces sprouting of sensory nerves. BDNF increases eosinophil chemotaxis levels in AD, inhibits apoptosis. NTs sensitize receptive nerve endings and upregulate neuronal neuropeptides and TRPV1.
$(60,64,114$,

S25, S26)

$(115$, S30-S33)

(25, S34-S36) 


\begin{tabular}{|c|c|c|c|c|}
\hline Opioids & $\begin{array}{l}\mu^{-}, \kappa^{-}, \delta-0 \text { pioid } \\
\text { receptors (partly } \\
\text { receptor-independent } \\
\text { cell activation) }\end{array}$ & Nerves, keratinocytes & $\begin{array}{l}\text { Antipruritic effect of } \mu \text {-opioid antagonists (central effect) } \\
\text { and } \kappa \text {-opioid agonists (spinal cord level). Opioid agonists } \\
\text { do not provoke itch upon injection or intradermal } \\
\text { application. } \mu \text {-Opioid receptor upregulation in } A D \text {. }\end{array}$ & $\begin{array}{l}(9,55 \\
116,117 \\
\text { S37) }\end{array}$ \\
\hline PACAP and VIP & VPAC receptors & $\begin{array}{l}\text { Autonomic and sensory } \\
\text { nerve fibers, lymphocytes, } \\
\text { dermal ECs, Merkel cells }\end{array}$ & $\begin{array}{l}\text { PACAP: involved in flush, vasodilatation, pain, } \\
\text { neurodegeneration; pruritus(?); induces release of } \\
\text { histamine from mast cells. VIP: histamine release from } \\
\text { mast cells, allodynia (no allodynia in AD) intensifies } \\
\text { ACh-induced itch in AD patients. }\end{array}$ & $\begin{array}{l}(59, \text { S38, } \\
\text { S39) }\end{array}$ \\
\hline Prostaglandins & $\begin{array}{l}\text { Prostanoid }(\mathrm{P}) \\
\text { receptors }\end{array}$ & $\begin{array}{l}\text { Sensory nerve fibers, } \\
\text { keratinocytes }\end{array}$ & $\begin{array}{l}\text { Prostaglandin E2 induces itch in humans but not } \\
\text { in mice. Prostaglandin D2 reduces IgE-mediated } \\
\text { scratching in mice. }\end{array}$ & $\begin{array}{l}(118, S 28, \\
\text { S40) }\end{array}$ \\
\hline
\end{tabular}

Stimuli are listed alphabetically. ${ }^{\mathrm{A} E n d o v a n i l l o i d s ~ i n c l u d e ~ h e a t, ~ a c i d o s i s, ~ e i c o s a n o i d s, ~ h i s t a m i n e, ~ b r a d y k i n i n, ~ e x t r a c e l l u l a r ~ A T P, ~ p r o s t a g l a n d i n s, ~ a n d ~}$ various neutrophins. AD, atopic dermatitis; BDNF, brain-derived neurotrophic factor; $\mathrm{CRH}$, corticotropin-releasing hormone; ET, endothelin; NK, neurokinin; NT, neurotrophin; PACAP, pituitary adenylate cyclase-activating polypeptide; POMC, pro-opiomelanocortin; VIP, vasoactive intestinal polypeptide; VPAC, VIP/PACAP receptor.

\section{There are many more peripheral itch-inducing stimuli than histamine}

A bewilderingly wide range of peripheral itch-inducing stimuli generated within or administered to the skin can trigger pruritus. The key message here is that the chorus of itch-inducing agents (Table 1) contains many more protagonists than the usual suspect, histamine. This includes several that are not yet widely appreciated as pruritic compounds or itch-relevant receptors (e.g., proteases, leukotrienes, ion channels, cytokines). The role of histamine, in contrast, is overestimated: small doses of histamine that fail to produce itch are still sufficient to produce edema and erythema upon intracutaneous injection, and nonsedative antagonists of the histamine receptors $\mathrm{H} 1$ and/or $\mathrm{H} 2$ have often been proven to be of low or no efficacy as antipruritic drugs (refs. 12-15; although others claim efficacy, refs. 16, 17), while other pruritogens (e.g., $\mathrm{pH}$ changes, opioids, proteases, cytokines, acetylcholine [ACh], and neurotrophins in atopic dermatitis patients; see Figure 1 and Table 1) are often more powerful itch inducers than histamine.

In addition, the dominant role of intracutaneous inflammation in itch pathogenesis, and the vicious cycles of neurogenic inflammation $(18,19)$ upregulating and perpetuating chronic itch, must be taken into account (see Itch is modulated by painful and nonpainful stimuli: role of opioid receptors). Also, the skin excels in extensive innervation of nonneuronal cells (e.g., keratinocytes, Merkel cells, and Langerhans cells in the epidermis and mast cells in the dermis), adding to the complexity of the signaling loops that have to be considered when investigating the pathogenesis of itch (4). Neurotrophins such as nerve growth factor (NGF) - copiously produced by, for example, the skin epithelium in order to direct and control sensory skin innervation (20), which is thought to be involved in the pathogenesis of prototypic pruritic dermatoses such as prurigo nodularis and atopic dermatitis (21-23) and whose therapeutic administration is pruritogenic (24) - nicely exemplify the complexity of itch pathogenesis and the cascades of itch-promoting events that render pruritus such a difficult-to-manage clinical problem. Upregulation of intracutaneous neurotrophin production and/or the expression of cognate receptors by inflammatory stimuli (e.g., in the context of atopic dermatitis) increases sensory innervation, lowers the itch threshold, upregulates the expression and/or sensitization of other receptor systems involved in itch pathogenesis (e.g., vanilloid receptors), upregulates the production of other pruritogenic agents (e.g., substance $\mathrm{P}[\mathrm{SP}]$ ), and perpetuates inflammation (e.g., by inducing mast cell degranulation and by forcing the affected individual to engage in a crescendo of scratching activity that further promotes skin inflammation; refs. 4, 19, 20, 25, 26).

Recently, however, additional histamine receptors have been discovered, and at least one of them - H4R - operates as an "itch receptor" in mice (27). This finding sheds new light on an old itch suspect and may explain why H1R antagonists are not efficient in certain pruritic skin diseases. This example also nicely illustrates why the study of pruritus has proven to be a field of endless fascination and discovery for clinicians, psychologists, pharmacologists, neurobiologists, endocrinologists, and neuroimmunologists alike.

\section{General limitations of an effective antipruritic therapy}

Evidently we need to engage in a lot of scratching our own brains until we can offer our itching patients more efficient, more individually tailored, safer, and better-tolerated itch management. Considerable progress has been achieved in the development of animal models for itch by changing from acute injection models to a disease-related approach (e.g., ref. 28). Nevertheless, specific animal models for many clinical itch conditions are still missing. Also the objective, reproducible quantification of itch is a much more tricky and treacherous art than one may suspect. Simple psychophysics using visual analog scales is still the gold standard, but it may best be combined with objective behavioral measurements using digital accelerometers or piezoelectronic devices (29). Thus far there are no sound indications that itch-specific genes exist. Finally, we face the lack of well-tolerated, easily administered, nonsedative compounds that selectively target dominant CNS "itch centers" - which probably do not exist anyway (see The enigmatic neurophysiology of itch is becoming increasingly understood).

Irrespective of these formidable limitations, it is rewarding, exciting, and important to scout for therapeutically promising frontiers in pruritus research - defining and redefining along the way the many intriguing open questions that just make you itch for more satisfactory answers.

\section{The enigmatic neurophysiology of itch is becoming increasingly understood}

The neurophysiological basis for the itch sensation was unclear for decades. Several competing theories coexisted until itch-selective neurons were found in humans, which explained the histamineinduced itch sensation (11). Slowly conducting C-fibers that trans- 


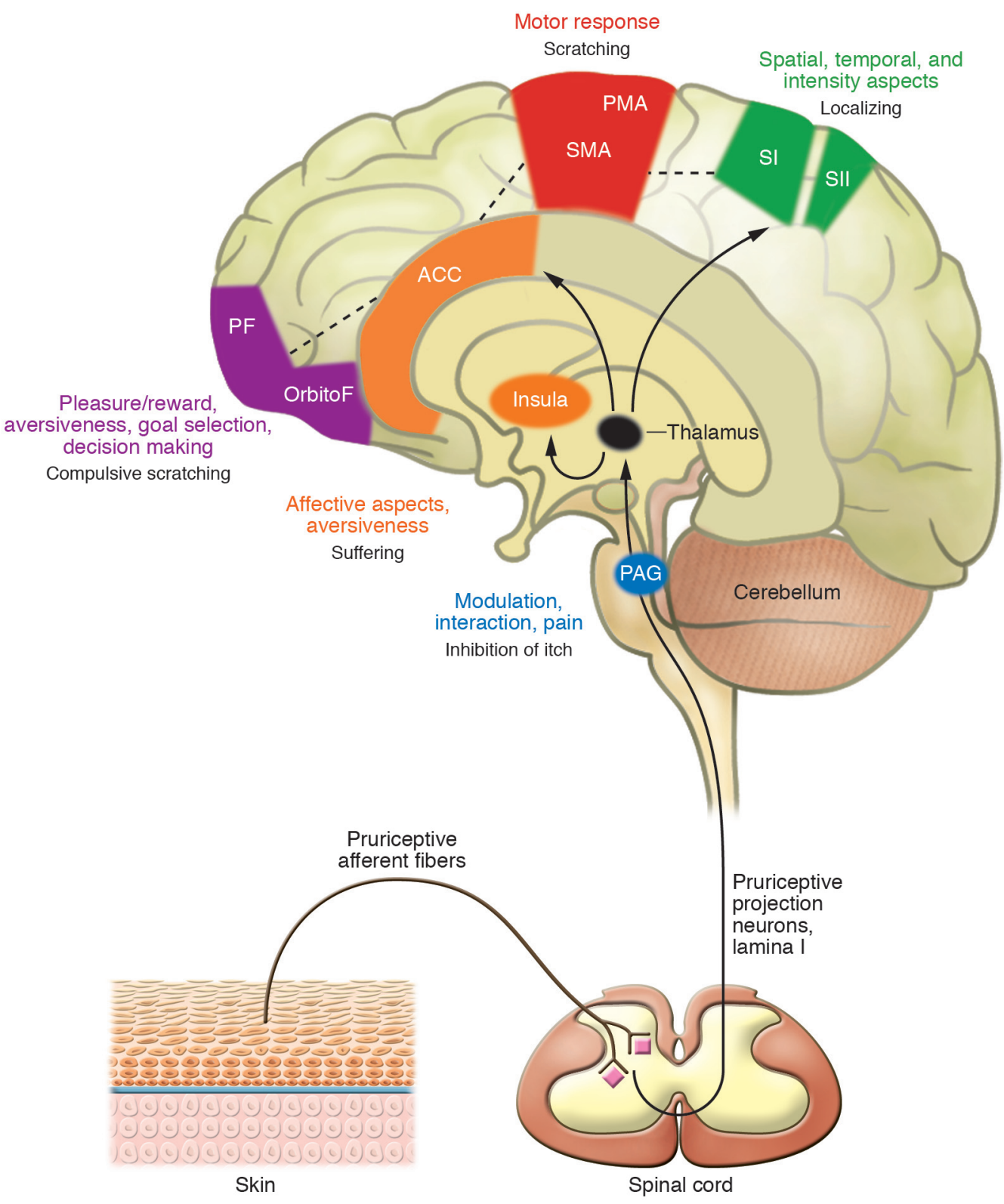

Figure 2

Central processing of pruritus. Pruriceptive primary afferent nerve fibers from the skin activate spinal neurons in lamina I of the dorsal horn, which project to the thalamus. Direct excitatory connections from the thalamus include anterior cingulate cortex (ACC), insular cortex (Insula), and primary and secondary somatosensory cortices (SI, SII). The putative function of brain areas activated in central imaging studies of itch are summarized. SMA, supplementary motor area; PMA, premotor area; PF, prefrontal cortex; OrbitoF, orbitofrontal cortex; PAG, periaqueductal gray.

duce itch signals have been discovered among the group of mechanoinsensitive C-afferents in healthy subjects and itch patients (30), suggesting a specific pathway for itch. In contrast, the most common type of C-fibers, mechano-heat-sensitive polymodal nociceptors, do not show prolonged activation by histamine and are related to pain processing $(31,32)$. The histamine-sensitive itch fibers, also known as pruriceptors, are characterized by a particularly low conduction velocity, large innervation territories, mechanical unresponsiveness, high transcutaneous electrical thresholds, and generation of an axon reflex erythema (11,32-35). However, this histamine-sensitive fiber class cannot account for all aspects of pruritus, particularly the mechanically evoked classification. Thus other classes of primary afferents must be involved in the histamineindependent generation of pruritus (36). This diversity of primary afferent "itch fibers" would nicely fit to the different submodalities of pruritus ("itch quality") observed in patients $(37,38, \mathrm{~S} 6)$.

The concept that dedicated pruritogenic neurons exist has been extended by recordings in the cat spinal cord. These results have demonstrated the existence of a specialized class of mechanically insensitive, histamine-sensitive dorsal horn neurons projecting to the thalamus (9). Thus the combination of dedicated peripheral and central neurons with a unique response pattern to pruritogenic 


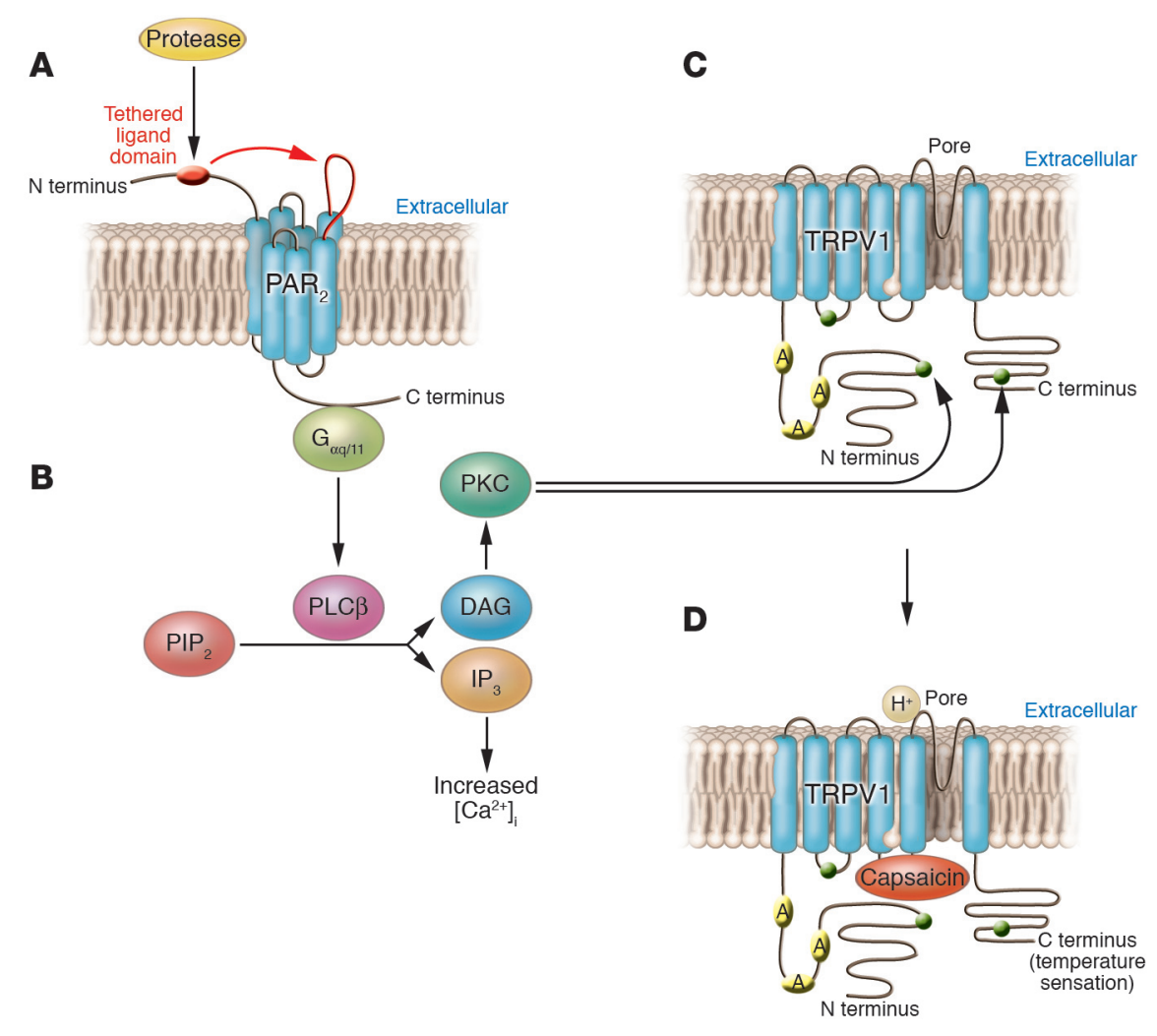

\section{Figure 3}

Pruritogenic receptors interact synergistically, thereby amplifying itch or pain. (A) Activation of $\mathrm{PAR}_{2}$ leads to binding of $G$ proteins $\left(\mathrm{G}_{\alpha \mathrm{\alpha} / 11}\right)$, followed by (B) stimulation of the intracellular PKC pathway and mobilization of intracellular $\left[\mathrm{Ca}^{2+}\right]$ via phopholipase $\mathrm{C} \beta$ (PLC $\left.\beta\right)$, diacylglycerol (DAG), and inositol triphosphate $\left(\mathrm{IP}_{3}\right)$. $\mathrm{PIP}_{2}$, phosphatidylinositol 4,5-biphosphate. This results in (C) sensitization of TRPV1 by phosphorylation of the intracellular $\mathrm{C}$ terminus (heterologous sensitization). Sensitization of TRPV1 leads to (D) a lowered threshold for capsaicin binding or temperature, i.e., stimulation of TRPV1. This mechanism affects release of neuropeptides (activation of mast cell degranulation) from nerve terminals of sensory nerves as well as stimulation of activation potentials (transmission of pain and pruritus to the spinal cord). mediators and anatomically distinct projections to the thalamus provides the basis for a specialized neuronal itch pathway.

Interestingly, these projection neurons do not exhibit spontaneous activity as the pain-processing projection neurons do. This lack of spontaneous activity may be due to active inhibition exerted by painprocessing neurons (8). Suppressing this inhibition might therefore provoke itch by a pure spinal mechanism - without any activation of primary afferent neurons from the skin (as seen in neuropathic and neurogenic pruritus). Thus one important challenge for more effective itch management will be to develop drugs that selectively upregulate the spinal inhibition of itch signals arriving from the skin.

The itch-selective spinal neurons form a distinct pathway projecting from lamina I of the spinal cord to the ventrocaudal part of the nucleus medialis, which projects to the anterior cingulate and dorsal insular cortex $(9,39)$ (Figure 2). The supraspinal processing of itch and its corresponding scratch response in humans have recently been investigated by functional PET (fPET) and functional MRI (fMRI). Here induction of itch by histamine application coactivates the anterior cingulate and insular cortex, premotor and supplementary motor areas, cerebellum, primary somatosensory cortex, and thalamus (40-42). As done earlier for pain sensation, particular aspects of the itch sensation have been correlated with the activation of certain brain areas: spatial and temporal aspects may be processed in the primary somatosensory cortex, planning of the scratch response in the premotor and supplementary motor cortices, and affective and motivational aspects in the anterior cingulate $(38,43)$ and insular cortex (Figure 2). All these brain areas are also involved in pain processing (44). Thus differences between pain and itch processing likely do not result from activation of distinct brain centers, but reflect a different activation pattern of basically identical centers. For example, itch processing may be characterized by weaker activation of pri- mary and secondary somatosensory cortices but relatively stronger activation of ipsilateral motor areas and anterior cingulate compared with pain sensation.

When the modulation of itch by painful cold stimuli was examined by $\mathrm{FPET}$, the periaqueductal gray matter was activated only when painful and itching stimuli were applied simultaneously (42). This activation was combined with reduced activity in the anterior cingulate, dorsolateral prefrontal cortex, and parietal cortex. This suggests that the periaqueductal gray, which is known for its role in endogenous pain inhibition, might also be involved in the central inhibition of itch by pain (Figure 2).

Studies with fMRI have largely confirmed activations that had been revealed by earlier PET results. However, they also found strong activation of prefrontal and orbitofrontal cortices (45, S7). These frontal brain areas are involved in reward systems and decision making but also in hedonic experiences (46); their activation might contribute to the compulsive component and thereby further increase the multidimensionality of the itch sensation.

Given the complex activation pattern and the broad overlap of pain processing, a clear anatomical target for centrally acting antipruritic therapy is lacking. Also, identification of pharmacological targets will require more specific imaging techniques, such as ligand-PET. This already has been successfully used to localize receptor density and to verify genetic differences in occupancy of opioid receptors (47). Though this has increased our understanding of how acute experimental itch is processed, central imaging has not yet identified critical anatomic or pharmacologic targets in clinical pruritus. Therefore, imaging studies in itch patients are urgently required, although as one can learn from the pain field, such studies are much more complex and difficult to interpret than the simplistic experimental setting using itch models in healthy volunteers. 


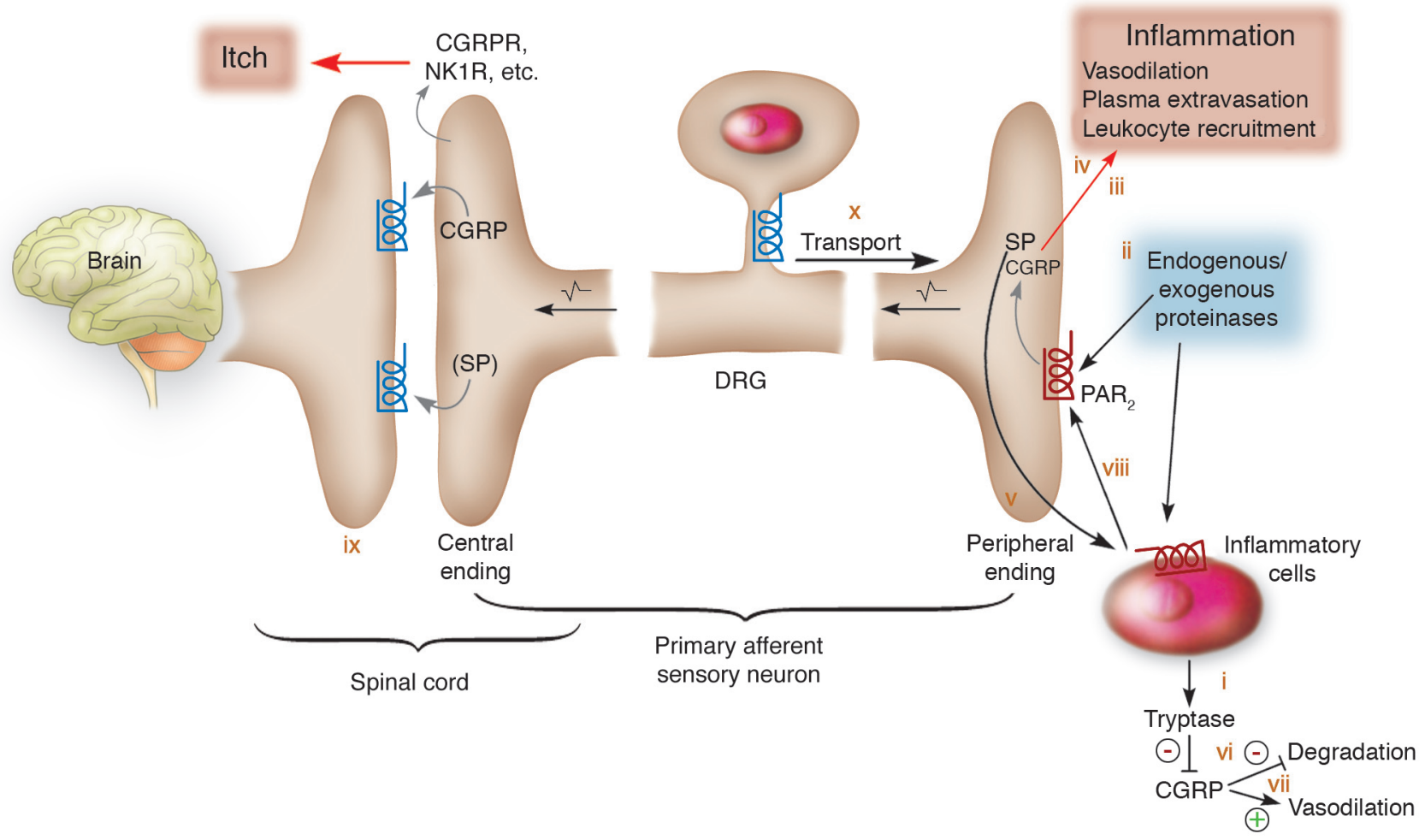

Figure 4

PARs play a key role in pruritus during neurogenic inflammation. (i) Tryptase released from degranulated mast cells activates $\mathrm{PAR}_{2}$ at the plasma membrane of sensory nerve endings. (ii) Activation of $\mathrm{PAR}_{2}$ by tryptase, trypsins, kallikreins, or probably exogenous proteinases (bacteria, house dust mite) stimulates the release of calcitonin gene-related peptide (CGRP) and tachykinins, e.g., SP, from sensory nerve endings. (iii) CGRP interacts with the $\mathrm{CGRP}_{1}$ receptor to induce arteriolar dilation and hyperaemia. (iv) SP interacts with the neurokinin-1 receptor (NK1R) on endothelial cells of postcapillary venules to cause gap formation and plasma extravasation. Hyperaemia and plasma extravasation cause edema during inflammation. (v) SP may stimulate degranulation of mast cells, providing a positive-feedback mechanism. (vi) Tryptase degrades CGRP and terminates its effects. (vii) CGRP inhibits SP degradation by neutral endopeptidase and also enhances SP release, thereby amplifying its effects. (viii) Mediators from mast cells and other inflammatory cells stimulate the release of vasoactive peptides from sensory nerves and also sensitize nerves. (ix) At the spinal cord level, $\mathrm{PAR}_{2}$-induced intracellular $\mathrm{Ca}^{2+}$ mobilization leads to release of CGRP (and SP) from central nerve endings, thereby activating CGRP receptor (CGRPR) and NK1R to transit itch responses to the central nervous system. ( $\mathrm{x}$ ) During inflammation, $\mathrm{PAR}_{2}$ may be peripherally transported, thereby increasing receptor density and stimulation. Figure modified with permission from Nature Medicine $(64,125)$.

\section{Itch is modulated by painful and nonpainful stimuli: role of opioid receptors}

It is common experience that the itch sensation can be reduced by scratching. The inhibition of itch by painful stimuli has been experimentally demonstrated by use of various painful thermal, mechanical, and chemical stimuli (S8). Painful electrical stimulation reduced histamine-induced itch for hours in an area spanning 10 centimeters beyond the site of stimulus, suggesting a central mode of action (48). Recent results suggest that noxious heat stimuli and scratching produce a stronger itch inhibition than do noxious cold stimuli (49).

On the contrary, analgesia may reduce the inhibition of itch by pain, thus enhancing pruritus (50). This phenomenon is particularly relevant to spinally administered $\mu$-opioid receptor agonists, which induce segmental analgesia often combined with segmental pruritus (31). Conversely, $\mu$-opioid antagonists have antipruritic effects in experimentally induced itch (S9) and also in patients with cholestatic itch. Remarkably, in some cholestatic patients treated with naloxone, the reduction of itch is accompanied by the induction of pain (51) and withdrawal-like reactions (52). This suggests an upregulation of endogenous opioids in these patients.
In contrast to strong analgesic and pruritic spinal effects of $\mu$ opioids, an inhibition of both pain and itch - albeit weaker - is observed in the periphery $(46,53,54)$. The role of nonneuronal opioid receptors and the secondary release of endogenous opioids (see Additional TRP channels are interesting targets in pruritus management) for the modulation of pruritus is as yet unclear. For example, it has been speculated that internalization of the $\mu$-opiate receptor in the epidermis of patients with atopic dermatitis may lead to the availability of free opioid ligands, which then induce chronic pruritogenic signals via altered unmyelinated nerve C-fibers $(4,55)$.

\section{Chronic skin inflammation causes peripheral sensitization to itch}

It has been known for decades that acute or chronic skin inflammation lowers the threshold for pruritic stimuli and thus causes peripheral itch sensitization $(56, \mathrm{~S} 2)$. The complex mechanisms underlying these phenomena (wheal, flare, edema) are becoming better understood. During inflammation, several cells release mediators that potentially bind to and activate high-affinity receptors on sensory neurons. Upon stimulation, mast cells release his- 

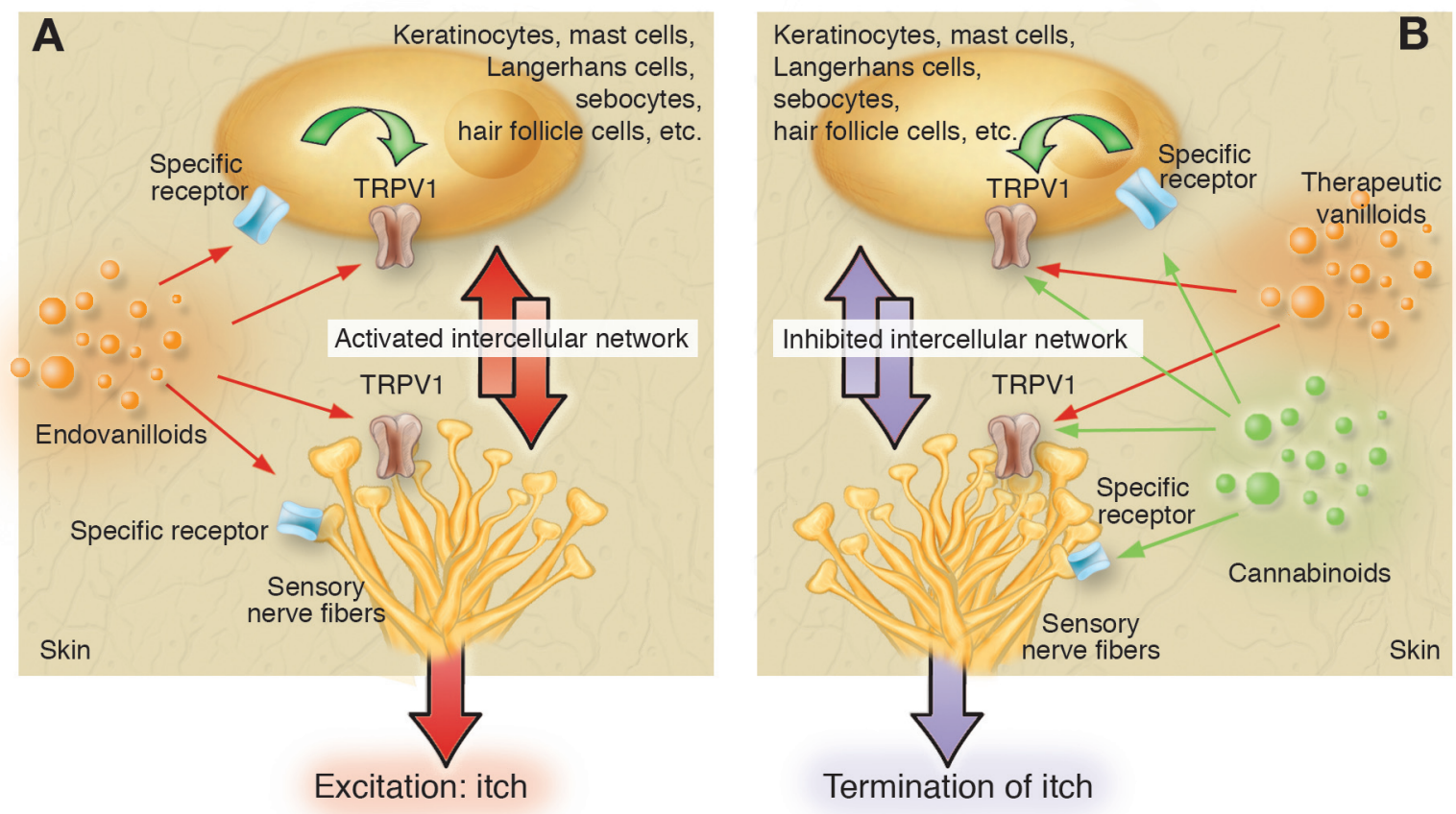

Figure 5

The putative role of TRPV1 signaling in the pathogenesis and therapy of itch. (A) Pruritogenic endovanilloids either directly or indirectly (via their own cognate receptors) activate and/or sensitize TRPV1 expressed on sensory neurons and nonneuronal cell types, which augments the bidirectional intercellular network to initiate itch. (B) Repeatedly applied topical vanilloids (such as capsaicin) may desensitize neuronal and nonneuronal TRPV1-mediated signaling so as to counteract the pruritogenic intercellular network and hence terminate itch. Note that certain cannabinoids (via acting either on specific CB receptors or directly on TRPV1) may augment the efficacy of vanilloid therapy.

tamine, tryptase, TNF- $\alpha$, prostaglandins, and/or leukotrienes; keratinocytes release $\mathrm{ACh}$, proteases, or $\beta$-endorphin; endothelial cells release kinins and protease-IV; and T cells release IL-2, IL-6, or IL-31, among others (Figure 1 and Table 1) $(18,19)$.

Peripheral sensory nerve endings express an armada of receptors that are involved in both inflammation and itch (Figure 1 and Table 1). Thus prolonged stimulation of itch receptors in the inflammatory environment may cause peripheral sensitization to itch. So far, less is known about the communication among the different neuronal receptors. For example, neuronal receptors such as transient receptor potential (TRP) vanilloid-type 1 (TRPV1) and proteinase-activated receptor $2\left(\mathrm{PAR}_{2}\right)$ may potentiate pain or pruritus by transactivation (Figure 3) (refs. 57, 58; reviewed in refs. 59-63, S10). Thus one wonders whether inhibitors of TRPV1 and/or PAR 2 (see Proteinase-activated receptors play a key role in pruritus during neurogenic inflammation) alleviate inflammation-associated (pruritogenic) itch.

\section{Proteinase-activated receptors play a key role in pruritus during neurogenic inflammation}

In fact, we have learned that proteases are more than just "scissors of destruction"; rather, they are representative of a group of mediators that communicate with nerves, thereby modulating inflammation, pain, and pruritus $(64,65)$. Similar to histamine or prostaglandins, certain proteases act as signaling molecules by activating PARs $(66$, S11). Proteases from plants (e.g., pollen), mites (e.g., house dust mite), or inflammatory cells (e.g., mast cell tryptase) can induce pruritus and/or inflammation (Figure 4; reviewed in ref. 60). $\mathrm{PAR}_{2}$, which can be activated by tryptase during inflammation or hypersensitivity, mediates neurogenic inflammation reflected by edema, plasma extravasation, and recruitment of leukocytes $(64,67)$. Interestingly, tryptase and $\mathrm{PAR}_{2}$ are upregulated on sensory nerves during atopic dermatitis, and $\mathrm{PAR}_{2}$ agonists induce pruritus in these patients, suggesting that $\mathrm{PAR}_{2}-$ similar to histamine receptors - is a receptor for "itchy" proteases (68). It is unknown whether $\mathrm{PAR}_{1}$ and $\mathrm{PAR}_{4}$ are also involved in the itch pathway and under which circumstances proteases may induce pain, inflammation, or pruritus. From first indications, it seems to be a matter of protease concentration (69). Since $\mathrm{PAR}_{2}$ is not only expressed in peripheral neurons but also in the spinal cord and brain, protease inhibitors and antagonists of $\mathrm{PAR}_{2}$ may be important tools for the treatment of itch with or without acute or chronic inflammation.

\section{Chronic skin inflammation may cause central itch sensitization}

Recent findings shed new light on the role of chronic inflammatory stimuli in pruritus with special regard to central sensitization of itch fibers. Activity in pruriceptors not only provokes itch but additionally facilitates spinal itch processing, resulting in touchor brush-evoked pruritus around an itching site (itchy skin) (S2, $\mathrm{S} 12)$. It requires ongoing activity in primary afferents and is most probably elicited by low-threshold mechanoreceptors (A- $\beta$ fibers) (S12, S13). Moreover, even normally painful stimuli can be misinterpreted as itch in a chronic itch condition when applied directly to pruritic skin lesions $(48,56)$.

Ongoing activity of pruriceptors, which presumably underlies central sensitization for itch, has already been confirmed microneurographically in a patient with chronic pruritus (30). In addition, lasting activation of pruriceptors by histamine has been shown to experimentally induce central sensitization for itch in 


\section{Table 2}

Frontiers in itch research and possible therapeutic consequences

Frontier

Similar spinal or supraspinal sensitization processes

in chronic pain and itch

Similar peripheral sensitization processes in

inflammatory pain and itch (e.g., NGF)

Effects of proteases in pain and itch; role of $\mathrm{PAR}_{2}$

Understanding the complexity of the CNS when

processing itch

Understanding the role of the epidermis in itch sensation

Role of neuronal cytokine receptors in itch sensation

Role of TRPV1 in the pathogenesis of itch

Role of TRP channels in itch
Possible therapeutic consequence

Selected

references

Antipruritic treatment with typical analgesics for neuropathic pain

(e.g., gabapentin, antidepressants)

Anti-NGF treatment for inflammatory pain and itch

$(119$, S41)

Serine protease inhibitors or antagonists of $\mathrm{PAR}_{2}$ for treatment of inflammatory itch and pain

Identifying new central targets in the itch pathway

Antipruritic treatment using modifiers of keratinocyte function and epidermal barrier dysfunction

Antipruritic therapy using specific cytokine suppressors

Antipruritic treatment using natural TRPV1 agonists such as modified forms of capsaicin or resiniferatoxin

Antipruritic treatment using thermal therapy healthy volunteers (56). Thus there is emerging evidence for a role of central sensitization in itch modulation during chronic pruritus. As there are many mediators and mechanisms that are potentially algogenic in inflamed skin (70), many of them could provoke itch in a sensitized patient.

\section{Psychoemotional stress triggers or enhances itch}

Clinically, it has long been appreciated that both acute stress (stressful life events) and chronic psychoemotional stress can trigger or enhance pruritus $(18,19,71)$. Recent insights into the neuroendocrinology and neuroimmunology of stress responses have improved our understanding of why this may happen. Stress responses are known to be learned, to involve cortical centers, and to activate the hypothalamus-pituitary-adrenal axis $(72,73)$. Since stress responses can be reprogrammed (e.g., by behavioral and neuropharmacologi$\mathrm{cal} /$ neuroendocrine therapy), deeper knowledge of the mechanisms underlying central itch control may lead to novel, innovative, psychosomatic, or neuropharmacological approaches for behavioral itch therapy. There is much to be learned about stress-induced itch from stress-related analgesia (74). Independent of direct effects of stress hormones (e.g., adrenocorticotropin-releasing hormone, cortisol, noradrenaline), the activation of endogenous pain-inhibitory systems, part of which are naloxone sensitive (75), should directly enhance itch processing by reducing its inhibition.

Moreover, the experience of increased itch upon stressful events would also lead to conditioning of itch and thereby aggravate and perpetuate stress-induced itch. For example, a close relationship between itch and psychological factors has been demonstrated in hand dermatoses, especially in patients who were convinced that stress was a major trigger of their disease (76).

The important role of learning processes in the development of chronic pain has been recognized (77) and resulted in the development of successful operant behavioral treatment regimens (S14) for chronic pain patients. Although there is evidence for clinically relevant learning effects in chronic itch (S15), the formation and reprogramming of itch memory has not yet been systematically explored.

\section{Endovanilloids and the TRPV1 ion channel are promising targets for antipruritic therapy}

A novel putative mechanism in the pathogenesis of itch has recently emerged. Certain itch mediators - such as eicosanoids, histamine, bradykinin, ATP, and various neurotrophins (78-81) - can be collectively coined as having endovanilloid functions (82). These agents, along with other potentially pruritogenic stimuli such as mild heat $\left(>43^{\circ} \mathrm{C}\right)$ and acidosis, either directly or indirectly activate and/or sensitize TRPV1 $(78,83,84)$.

TRPV1 belongs to the superfamily of TRP channels, which is composed of 6 groups of molecules: the canonical (TRPC), the vanilloid (TRPV), the melastatin (TRPM), the polycystin (TRPP), the mucolipin (TRPML), and the ankyrin transmembrane protein 1 (TRPA) subfamilies. In general, these molecules act as nonselective calciumpermeable sensory transduction channels detecting, for example, temperature and osmotic/mechanical changes (reviewed in ref. 85).

TRPV1 was originally described as appearing on nociceptive sensory neurons (83) as a central integrator of various pain-inducing stimuli. Besides endovanilloid-induced activation (Figures 3 and 5), TRPV1 can be effectively activated by capsaicin, the pungent ingredient of hot chili peppers. TRPV1 activation first excites (84), then desensitizes, the sensory afferents - an effect that establishes the basis for the therapeutic application of vanilloids to mitigate pain and itch $(3, \mathrm{~S} 16)$. Vanilloid administration results in a depletion of neuropeptides (such as SP) in the C-fibers, which suspends the interplay between skin sensory neurons and mast cells (Figure 1) $(3,6,10)$. Indeed, topical capsaicin suppresses histamine-induced itch (86) and is increasingly used in the therapy of pruritus in numerous skin diseases (reviewed in refs. 3, 6, 87).

A new itchy twist has recently propelled TRPV1 research beyond its confinement to sensory physiology: functional TRPV1 channels are now recognized to be expressed by numerous nonneuronal cell types, including human epidermal and hair follicle keratinocytes, dermal mast cells, and dendritic cells (88-90). TRPV1 activation - besides markedly affecting keratinocyte proliferation, differentiation, and apoptosis - results in the release of pruritogenic cytokine mediators from these nonneuronal cells $(91,92)$. 
These findings invite researchers to postulate that, besides activating their own cognate receptors (Table 1), the endovanilloid itch mediators also activate and/or sensitize TRPV1 expressed on itch-specific sensory neurons (to fire action potentials) and many other skin cells (to upregulate the release of pruritogenic substances; Figure 5A) (4). In consequence, repeatedly applied topical capsaicin, or other therapeutically promising vanilloids, may desensitize neuronal and nonneuronal TRPV1-mediated signaling so as to counteract pruritogenic intercellular signaling (Figure 5B). In fact, TRPV1 expression is dramatically increased in lesional epidermal keratinocytes of prurigo nodularis patients (90), and topical capsaicin is effective in this intensely pruritic disease characterized by vicious cycles of neurogenic inflammation and neurotrophininduced nerve sprouting $(3,93, \mathrm{~S} 1)$.

The most notorious clinical limitation of capsaicin application is the burning sensation. Therefore, better TRPV1 agonists that cause only a minor excitation but are still potent desensitizers are needed. A chief candidate is resiniferatoxin (S17), which is 3 times more potent as a desensitizer (i.e., to treat pain and itch) than as an excitatory agent (i.e., to cause pain) (S16). Alternatively, TRPV1 antagonists (such as capsazepine or iodo-resiniferatoxin; S16) deserve more attention as potential antipruritic agents.

\section{Are endocannabinoids involved in itch pathogenesis?}

The cannabinoid system (94) provides another putative itch frontier. Cannabinoid receptor 1 (CB1) and TRPV1 show marked colocalization in sensory neurons (94). Moreover, CB1 agonists effectively suppress histamine-induced pruritus (95), suggesting the involvement of CB1 signaling in the initiation of itch. Furthermore, under inflammatory conditions (96) cannabinoids also activate the TRPV1 pathway and thereby switch their neuronal effect from inhibition (97) to excitation and sensitization (Figure 3) (98). Finally, since CBs, just like TRPV1, are also expressed by nonneuronal human skin cells $(99,100)$, CBs may be involved in the neuronal/nonneuronal cellular network of pruritogenic stimuli arising in skin. Thus coadministration of a TRPV1 agonist with a CB1 agonist would be expected to serve as a potent antipruritic regimen (Figure $5 \mathrm{~B}$ ). In addition, this would prevent the acute burning sensation initiated by capsaicin, since CB agonists (e.g., anandamide and HU210) prevent the excitation induced by capsaicin $(101,102)$.

\section{Additional TRP channels are interesting targets in pruritus management}

The fact that cold generally alleviates itch while increasing temperature tends to aggravate it $(3, \mathrm{~S} 1)$ draws our attention to other members of the TRPV subfamily (TRPV2, TRPV3, and TRPV4). These channels operate as cellular temperature sensors, since all are activated by differential temperatures (103-105). TRPV3 shows a very similar neuronal expression pattern to that of TRPV1, and TRPV3 subunits may form heteromultimeric structures by interacting with TRPV1 monomers (105). Therefore, TRPV3 may act as signal cotransducer and/or regulator of TRPV1-mediated pain and itch.

Most intriguingly, quite like TRPV1, functional TRPV2, TRPV3, and TRPV4 channels are highly expressed by epidermal keratinocytes and mast cells $(104,106-108)$. Moreover, TRPV4 is activated by such lipid peroxidation products as eicosanoids, which function as TRPV1-activating pruritogenic substances (109). Physical and thermal activation of TRPV2 causes mast cells to degranulate, which depends on protein kinase A-related signaling (107) - one of the chief mechanisms in initiating pain- and itch-inducing TRPV1 sensitization (81).

Finally, TRPM8 receptors deserve to be mentioned. Expressed by $\mathrm{C}$-type sensory neurons, they serve as thermosensors for coolness and cold (i.e., $8^{\circ} \mathrm{C}$ to $-28^{\circ} \mathrm{C}$ ). TRPM8 is also activated by chemicals - menthol, menthol analogs, and icilin (S18) - that produce sensations of cold (110). Menthol has a long tradition in topical anti-itch therapy (albeit with moderate success; ref. S1), and in an animal model of scratching provoked by a magnesium-deficient diet, topical icilin significantly reduced excoriations in hairless rats (4). In short, all of these receptors warrant systematic exploration of their nonthermosensor, itch-related signaling roles.

\section{Conclusion and perspectives}

This exploration of recent frontiers in pruritus research reveals that we still lack a single, universally effective pharmacological handle on combating itch and that, due to the inherent neurophysiological and neuroimmunological complexity of itch pathophysiology, it would be naive to expect that such a one-shot cure of itch will become available any time soon. However, the complexity of the interactions between the central and peripheral nervous system and the skin in producing this symptom notwithstanding, a broad but concrete spectrum of molecular targets for effective itch intervention has moved into view. If these "hot spot" molecules, both in the CNS and peripheral nervous system, are further explored systematically, we undoubtedly will move much closer to developing more effective therapeutic combination strategies for pruritus management.

In particular, it has become apparent that timely combination approaches that target both the peripheral production of inflammation-induced itch signals and the peripherally incited vicious cycles that perpetuate itch and cause spinal and central sensitization to itch are needed. Thus the combination of peripherally active antiinflammatory agents with drugs that counteract chronic central itch sensitization is a particularly sensible approach beyond the antihistamine horizon. Table 2 concludes this excursion by summarizing some of our current personal favorites among the "itch frontiers," which we expect to pave the way for the development of innovative and more effective approaches to itch management in the future.

\section{Acknowledgments}

The authors gratefully acknowledge the administrative assistance of C. Mess and C. Moormann in putting the finishing touches to this Review and the support of Deutsche Forschungsgemeinschaft (Pa 345/11-2 to R. Paus; STE 1014/2-1 and IZKF Stei2/027/06 to M. Steinhoff; and KGF 107 to M. Schmelz) and Hungarian Scientific Research Fund (OKTA K63153 to Tamás Bíró), which have aided the writing of this Review.

Note: References S1-S42 are available online with this article; doi:10.1172/JCI28553DS1.

Address correspondence to: Ralf Paus, Department of Dermatology, University Hospital Schleswig-Holstein, Campus Lübeck, University of Lübeck, D-23538 Lübeck, Germany. Phone: 49-451500-2543; Fax: 49-451-500-5161; E-mail: ralf.paus@uk-sh.de.

Martin Schmelz and Tamás Bíró contributed equally to this work. 
1. Greaves, M.W., and Khalifa, N. 2004. Itch: more than skin deep. Int. Arch. Allergy Immunol. 135:166-172.

2. Graham, D.T., Goodell, H., and Wolff, H.G. 1951. Neural mechanisms involved in itch, itchy skin, and tickle sensations. J. Clin. Invest. 30:37-49.

3. Yosipovitch, G., Greaves, M.W., and Schmelz, M. 2003. Itch. Lancet. 361:690-694.

4. Biro, T., et al. 2005. How best to fight that nasty itch - from new insights into the neuroimmunological, neuroendocrine, and neurophysiological bases of pruritus to novel therapeutic approaches. Exp. Dermatol. 14:225-240.

5. Steinhoff, M., et al. 2006. Neurophysiological, neuroimmunological and neuroendocrine basis of pruritus. J. Invest. Dermatol. In press.

6. Twycross, R., et al. 2003. Itch: scratching more than the surface. $O J M$. 96:7-26.

7. Bromm, B., Scharein, E., and Vahle-Hinz, C. 2000 Cortex areas involved in the processing of normal and altered pain. Prog. Brain Res. 129:289-302.

8. Schmelz, M. 2001. A neural pathway for itch. Nat. Neurosci. 4:9-10.

9. Andrew, D., and Craig, A.D. 2001. Spinothalamic lamina I neurons selectively sensitive to histamine: a central neural pathway for itch. Nat. Neurosci. 4:72-77

10. Stander, S., and Steinhoff, M. 2002. Pathophysiology of pruritus in atopic dermatitis: an overview. Exp. Dermatol. 11:12-24.

11. Schmelz, M., Schmidt, R., Bickel, A., Handwerker, H.O., and Torebjork, H.E. 1997. Specific C-receptors for itch in human skin. J. Neurosci. 17:8003-8008.

12. Klein, P.A., and Clark, R.A. 1999. An evidence-based review of the efficacy of antihistamines in relieving pruritus in atopic dermatitis. Arch. Dermatol. 135:1522-1525.

13. Munday, J., et al. 2002. Chlorpheniramine is no more effective than placebo in relieving the symptoms of childhood atopic dermatitis with a nocturnal itching and scratching component. Dermatology. 205:40-45

14. Rukwied, R., Lischetzki, G., McGlone, F., Heyer, G., and Schmelz, M. 2000. Mast cell mediators other than histamine induce pruritus in atopic dermatitis patients: a dermal microdialysis study. $\mathrm{Br}$. J. Dermatol. 142:1114-1120.

15. Hanifin, J.M. 1990. The role of antihistamines in atopic dermatitis. J. Allergy Clin. Immunol. 86:666-669.

16. Imaizumi, A., Kawakami, T., Murakami, F., Soma, Y., and Mizoguchi, M. 2003. Effective treatment of pruritus in atopic dermatitis using $\mathrm{H} 1$ antihistamines (second-generation antihistamines): changes in blood histamine and tryptase levels. J. Dermatol. Sci. 33:23-29.

17. Monroe, E.W. 1992. Relative efficacy and safety of loratadine, hydroxyzine, and placebo in chronic idiopathic urticaria and atopic dermatitis. Clin. Ther. 14:17-21.

18. Arck, P.C., Slominski, A., Theoharides, T.C., Peters, E.M.J., and Paus, R. 2006. Neuroimmunology of stress: skin takes center stage. J. Invest. Dermatol. 126. In press

19. Paus, R., Theoharides, T.C., and Arck, P.C. 2006 Neuroimmunoendocrine circuitry of the 'brainskin connection'. Trends Immunol. 27:32-39.

20. Botchkarev, N.V., et al. 2006. Neurotrophins in skin biology. J. Invest. Dermatol. 2:31-36.

21. Lee, M.R., and Shumack, S. 2005. Prurigo nodularis: a review. Australas. J. Dermatol. 46:211-218; quiz 219-220.

22. Johansson, O., Liang, Y., and Emtestam, L. 2002. Increased nerve growth factor- and tyrosine kinase A-like immunoreactivities in prurigo nodularis skin -- an exploration of the cause of neurohyperplasia. Arch. Dermatol. Res. 293:614-619.

23. Tanaka, A., and Matsuda, H. 2005. Expression of nerve growth factor in itchy skins of atopic NC/ NgaTnd mice. J. Vet. Med. Sci. 67:915-919.

24. Aloe, L. 2004. Rita Levi-Montalcini: the discovery of nerve growth factor and modern neurobiology. Trends Cell Biol. 14:395-399.

25. Groneberg, D.A., et al. 2005. Gene expression and regulation of nerve growth factor in atopic dermatitis mast cells and the human mast cell line-1. J. Neuroimmunol. 161:87-92.

26. Toyoda, M., et al. 2002. Nerve growth factor and substance $P$ are useful plasma markers of disease activity in atopic dermatitis. Br. J. Dermatol. 147:71-79.

27. Bell, J.K., McQueen, D.S., and Rees, J.L. 2004. Involvement of histamine $\mathrm{H} 4$ and $\mathrm{H} 1$ receptors in scratching induced by histamine receptor agonists in Balb C mice. Br. J. Pharmacol. 142:374-380.

28. Seike, M., Ikeda, M., Kodama, H., Terui, T., and Ohtsu, H. 2005. Inhibition of scratching behavior caused by contact dermatitis in histidine decarboxylase gene knockout mice. Exp. Dermatol. 14:169-175.

29. Rees, J., and Murray, C.S. 2005. Itching for progress. Clin. Exp. Dermatol. 30:471-473.

30. Schmelz, M., et al. 2003. Active "itch fibers" in chronic pruritus. Neurology. 61:564-566.

31. Andrew, D., Schmelz, M., and Ballantyne, J.C. 2003. Itch - mechanisms and mediators. In Progress in pain research and management. J.O. Dostrovsky, D.B. Carr, and M. Koltzenburg, editors. ISAP Press. Seattle, Washington, USA. 213-226.

32. Schmelz, M., et al. 2003. Chemical response pattern of different classes of C-nociceptors to pruritogens and algogens. J. Neurophysiol. 89:2441-2448.

33. Weidner, C., et al. 1999. Functional attributes discriminating mechanoinsensitive and mechanoresponsive C nociceptors in human skin. J. Neurosci. 19:10184-10190.

34. Schmidt, R., Schmelz, M., Weidner, C., Handwerker, H.O., and Torebjork, H.E. 2002. Innervation territories of mechanoinsensitive $\mathrm{C}$ nociceptors in human skin. J. Neurophysiol. 88:1859-1866.

35. Schmelz, M., et al. 2000. Which nerve fibers mediate the axon reflex flare in human skin? Neuroreport. 11:645-648.

36. Ikoma, A., Handwerker, H., Miyachi, Y., and Schmelz, M. 2005. Electrically evoked itch in humans. Pain. 113:148-154.

37. Darsow, U., et al. 2001. New aspects of itch pathophysiology: component analysis of atopic itch using the 'Eppendorf Itch Questionnaire'. Int. Arch. Allergy Immunol. 124:326-331.

38. Darsow, U., et al. 2000. Processing of histamineinduced itch in the human cerebral cortex: a correlation analysis with dermal reactions. J. Invest. Dermatol. 115:1029-1033.

39. Craig, A.D. 2002. How do you feel? Interoception: the sense of the physiological condition of the body. Nat. Rev. Neurosci. 3:655-666

40. Hsieh, J.C., et al. 1994. Urge to scratch represented in the human cerebral cortex during itch.J. Neurophysiol. 72:3004-3008

41. Drzezga, A., et al. 2001. Central activation by histamine-induced itch: analogies to pain processing: a correlational analysis of $\mathrm{O}-15 \mathrm{H} 2 \mathrm{O}$ positron emission tomography studies. Pain. 92:295-305.

42. Mochizuki, H., et al. 2003. Imaging of central itch modulation in the human brain using positron emission tomography. Pain. 105:339-346.

43. Vogt, B.A., Vogt, L., and Laureys, S. 2006. Cytology and functionally correlated circuits of human posterior cingulate areas. Neuroimage. 29:452-466.

44. Apkarian, A.V., Bushnell, M.C., Treede, R.D., and Zubieta, J.K. 2005. Human brain mechanisms of pain perception and regulation in health and disease. Eur. J. Pain. 9:463-484.

45. Walter, B., et al. 2005. Brain activation by histamine prick test-induced itch. J. Invest. Dermatol. 125:380-382.

46. Kringelbach, M.L. 2005. The human orbitofrontal cortex: linking reward to hedonic experience. Nat. Rev. Neurosci. 6:691-702.

47. Zubieta, J.K., et al. 2003. COMT val158met genotype affects mu-opioid neurotransmitter responses to a pain stressor. Science. 299:1240-1243.

48. Nilsson, H.J., Levinsson, A., and Schouenborg, J. 1997. Cutaneous field stimulation (CFS): a new powerful method to combat itch. Pain. 71:49-55.

49. Yosipovitch, G., Fast, K., and Bernhard, J.D. 2005. Noxious heat and scratching decrease histamineinduced itch and skin blood flow. J. Invest. Dermatol. 125:1268-1272.

50. Atanassoff, P.G., et al. 1999. Enhancement of experimental pruritus and mechanically evoked dysesthesiae with local anesthesia. Somatosens. Mot. Res. 16:291-298.

51. McRae, C.A., et al. 2003. Pain as a complication of use of opiate antagonists for symptom control in cholestasis. Gastroenterology. 125:591-596.

52. Jones, E.A., Neuberger, J., and Bergasa, N.V. 2002. Opiate antagonist therapy for the pruritus of cholestasis: the avoidance of opioid withdrawal-like reactions. OJM. 95:547-552.

53. Stein, C., Schafer, M., and Machelska, H. 2003. Attacking pain at its source: new perspectives on opioids. Nat. Med. 9:1003-1008.

54. DeHaven-Hudkins, D.L., et al. 2002. Antipruritic and antihyperalgesic actions of loperamide and analogs. Life Sci. 71:2787-2796.

55. Bigliardi-Qi, M., Lipp, B., Sumanovski, L.T., Buechner, S.A., and Bigliardi, P.L. 2005. Changes of epidermal mu-opiate receptor expression and nerve endings in chronic atopic dermatitis. Dermatology. 210:91-99.

56. Ikoma, A., et al. 2003. Neuronal sensitization for histamine-induced itch in lesional skin of patients with atopic dermatitis. Arch. Dermatol. 139:1455-1458.

57. Amadesi, S., et al. 2004. Protease-activated receptor 2 sensitizes the capsaicin receptor transient receptor potential vanilloid receptor 1 to induce hyperalgesia. J. Neurosci. 24:4300-4312.

58. Moormann, C., et al. 2006. Functional characterization and expression analysis of the proteinaseactivated receptor- 2 in human cutaneous mast cells. J. Invest. Dermatol. 126:746-755

59. Steinhoff, M., et al. 2003. Modern aspects of cutaneous neurogenic inflammation. Arch. Dermatol. 139:1479-1488.

60. Steinhoff, M., et al. 2005. Proteinase-activated receptors: transducers of proteinase-mediated signaling in inflammation and immune response. Endocr. Rev. 26:1-43.

61. Vergnolle, N., Ferazzini, M., D’Andrea, M.R., Buddenkotte, J., and Steinhoff, M. 2003. Proteinaseactivated receptors: novel signals for peripheral nerves. Trends Neurosici. 26:496-500.

62. Szolcsanyi, J. 2004. Forty years in capsaicin research for sensory pharmacology and physiology. Neuropeptides. 38:377-384.

63. Grassberger, M., Steinhoff, M., Schneider, D., and Luger, T.A. 2004. Pimecrolimus -- an anti-inflammatory drug targeting the skin. Exp. Dermatol. 13:721-730.

64. Steinhoff, M., et al. 2000. Agonists of proteinaseactivated receptor 2 induce inflammation by a neurogenic mechanism. Nat. Med. 6:151-158.

65. Vergnolle, N., et al. 2001. Proteinase-activated receptor- 2 and hyperalgesia: a novel pain pathway. Nat. Med. 7:821-826.

66. Ossovskaya, V.S., and Bunnett, N.W. 2004. Proteaseactivated receptors: contribution to physiology and disease. Physiol. Rev. 84:579-621.

67. Su, X., Camerer, E., Hamilton, J.R., Coughlin, S.R., and Matthay, M.A. 2005. Protease-activated receptor- 2 activation induces acute lung inflammation by neuropeptide-dependent mechanisms. J. Immunol. 175:2598-2605. 
68. Shelley, W.B., and Arthur, R.P. 1955. Mucunain, the active pruritogenic proteinase of cowhage. Science. 122:469-470.

69. Obreja, O., Rukwied, R., Steinhoff, M., and Schmelz, M. 2006. Neurogenic components of trypsin- and thrombin-induced inflammation in rat skin, in vivo. Exp. Dermatol. 15:58-65.

70. Steen, K.H., Steen, A.E., and Reeh, P.W. 1995. A dominant role of acid $\mathrm{pH}$ in inflammatory excitation and sensitization of nociceptors in rat skin, in vitro. J. Neurosci. 15:3982-3989.

71. Gieler, U., Kupfer, J., Niemeier, V., and Brosig, B. 2003. Psyche and skin: what's new? J. Eur. Acad. Dermatol. Venereol. 17:128-130.

72. Slominski, A., and Wortsman, J. 2000. Neuroendocrinology of the skin. Endocr. Rev. 21:457-487.

73. McEwen, B., and Lasley, E.N. 2004. The end of stress as we know it. Dana Press. Washington, DC, USA. 239 pp.

74. Willer, J.C., Dehen, H., and Cambier, J. 1981. Stressinduced analgesia in humans: endogenous opioids and naloxone-reversible depression of pain reflexes. Science. 212:689-691.

75. Vaughan, C.W. 2005. Stressed-out endogenous cannabinoids relieve pain. Trends Pharmacol. Sci. 27:69-71.

76. Niemeier, V., Nippesen, M., Kupfer, J., Schill, W.B., and Gieler, U. 2002. Psychological factors associated with hand dermatoses: which subgroup needs additional psychological care? Br. J. Dermatol. 146:1031-1037.

77. Flor, H., Knost, B., and Birbaumer, N. 2002. The role of operant conditioning in chronic pain: an experimental investigation. Pain. 95:111-118.

78. Hwang, S.W., et al. 2000. Direct activation of capsaicin receptors by products of lipoxygenases: endogenous capsaicin-like substances. Proc. Natl. Acad. Sci. U. S. A. 97:6155-6160.

79. Chuang, H.H., et al. 2001. Bradykinin and nerve growth factor release the capsaicin receptor from PtdIns(4,5)P2-mediated inhibition. Nature. 411:957-962.

80. Shin, J., et al. 2002. Bradykinin-12-lipoxygenase-VR1 signaling pathway for inflammatory hyperalgesia. Proc. Natl. Acad. Sci. U. S. A. 99:10150-10155.

81. Mohapatra, D.P., and Nau, C. 2003. Desensitization of capsaicin-activated currents in the vanilloid receptor TRPV1 is decreased by the cyclic AMPdependent protein kinase pathway. J. Biol. Chem. 278:50080-50090.

82. Di Marzo, V., Blumberg, P.M., and Szallasi, A. 2002. Endovanilloid signaling in pain. Curr. Opin. Neurobiol. 12:372-379.

83. Caterina, M.J., et al. 1997. The capsaicin receptor: a heat-activated ion channel in the pain pathway. Nature. 389:816-824.

84. Caterina, M.J., and Julius, D. 2001. The vanilloid receptor: a molecular gateway to the pain pathway. Annu. Rev. Neurosci. 24:487-517.

85. Clapham, D.E. 2003. TRP channels as cellular sensors. Nature. 426:517-524.

86. Weisshaar, E., Heyer, G., Forster, C., and Handwerker, H.O. 1998. Effect of topical capsaicin on the cutaneous reactions and itching to histamine in atopic eczema compared to healthy skin. Arch. Dermatol. Res. 290:306-311.

87. Biro, T., Acs, G., Acs, P., Modarres, S., and Blumberg, P.M. 1997. Recent advances in understanding of vanilloid receptors: a therapeutic target for treatment of pain and inflammation in skin. J. Investig. Dermatol. Symp. Proc. 2:56-60.
88. Inoue, K., Koizumi, S., Fuziwara, S., Denda, S., and Denda, M. 2002. Functional vanilloid receptors in cultured normal human epidermal keratinocytes. Biochem. Biophys. Res. Commun. 291:124-129.

89. Bodo, E., et al. 2004. Vanilloid receptor-1 (VR1) is widely expressed on various epithelial and mesenchymal cell types of human skin. J. Invest. Dermatol. 123:410-413.

90. Stander, S., et al. 2004. Expression of vanilloid receptor subtype 1 in cutaneous sensory nerve fibers, mast cells, and epithelial cells of appendage structures. Exp. Dermatol. 13:129-139.

91. Southall, M.D., et al. 2003. Activation of epidermal vanilloid receptor- 1 induces release of proinflammatory mediators in human keratinocytes. J. Pharmacol. Exp. Ther. 304:217-222.

92. Bodo, E., et al. 2005. A hot new twist to hair biology: involvement of vanilloid receptor-1 (VR1/ TRPV1) signaling in human hair growth control. Am. J. Pathol. 166:985-998.

93. Stander, S., Luger, T., and Metze, D. 2001. Treatment of prurigo nodularis with topical capsaicin. J. Am. Acad. Dermatol. 44:471-478.

94. Klein, T.W. 2005. Cannabinoid-based drugs as anti-inflammatory therapeutics. Nat. Rev. Immunol. 5:400-411.

95. Dvorak, M., Watkinson, A., McGlone, F., and Rukwied, R. 2003. Histamine induced responses are attenuated by a cannabinoid receptor agonist in human skin. Inflamm. Res. 52:238-245.

96. Singh, M.E., McGregor, I.S., and Mallet, P.E. 2005. Repeated exposure to Delta(9)-tetrahydrocannabinol alters heroin-induced locomotor sensitisation and Fos-immunoreactivity. Neuropharmacology. 49:1189-1200

97. Akerman, S., Kaube, H., and Goadsby, P.J. 2004 Anandamide acts as a vasodilator of dural blood vessels in vivo by activating TRPV1 receptors. $B r . J$. Pharmacol. 142:1354-1360.

98. van der Stelt, M., et al. 2005. Anandamide acts as an intracellular messenger amplifying $\mathrm{Ca}(2+)$ influx via TRPV1 channels. EMBO J. 24:3517-3518.

99. Maccarrone, M., et al. 2003. The endocannabinoid system in human keratinocytes. Evidence that anandamide inhibits epidermal differentiation through CB1 receptor-dependent inhibition of protein kinase $\mathrm{C}$, activation protein-1, and transglutaminase. J. Biol. Chem. 278:33896-33903.

100.Stander, S., Schmelz, M., Metze, D., Luger, T., and Rukwied, R. 2005. Distribution of cannabinoid receptor 1 (CB1) and 2 (CB2) on sensory nerve fibers and adnexal structures in human skin. J. Dermatol. Sci. 38:177-188.

101.Richardson, J.D., Kilo, S., and Hargreaves, K.M. 1998. Cannabinoids reduce hyperalgesia and inflammation via interaction with peripheral CB1 receptors. Pain. 75:111-119.

102.Rukwied, R., Watkinson, A., McGlone, F., and Dvorak, M. 2003. Cannabinoid agonists attenuate capsaicin-induced responses in human skin. Pain. 102:283-288.

103.Caterina, M.J., Rosen, T.A., Tominaga, M., Brake, A.J., and Julius, D. 1999. A capsaicin-receptor homologue with a high threshold for noxious heat. Nature. 398:436-441.

104. Peier, A.M., et al. 2002. A heat-sensitive TRP channel expressed in keratinocytes. Science. 296:2046-2049.

105.Smith, G.D., et al. 2002. TRPV3 is a temperaturesensitive vanilloid receptor-like protein. Nature. 418:186-190.

106.Chung, M.K., Lee, H., Mizuno, A., Suzuki, M., and
Caterina, M.J. 2004. TRPV3 and TRPV4 mediate warmth-evoked currents in primary mouse keratinocytes. J. Biol. Chem. 279:21569-21575.

107. Stokes, A.J., Shimoda, L.M., Koblan-Huberson, M., Adra, C.N., and Turner, H. 2004. A TRPV2-PKA signaling module for transduction of physical stimuli in mast cells. J. Exp. Med. 200:137-147.

108. Moqrich, A., et al. 2005. Impaired thermosensation in mice lacking TRPV3, a heat and camphor sensor in the skin. Science. 307:1468-1472.

109. Watanabe, H., et al. 2003. Anandamide and arachidonic acid use epoxyeicosatrienoic acids to activate TRPV4 channels. Nature. 424:434-438.

110.McKemy, D.D., Neuhausser, W.M., and Julius, D. 2002. Identification of a cold receptor reveals a general role for TRP channels in thermosensation. Nature. 416:52-58.

111.Schmelz, M., Schmid, R., Handwerker, H.O., and Torebjork, H.E. 2000. Encoding of burning pain from capsaicin-treated human skin in two categories of unmyelinated nerve fibres. Brain. 123:560-571.

112.Slominski, A.T., et al. 1999. Cutaneous expression of CRH and CRH-R. Is there a "skin stress response system?” Ann. N. Y. Acad. Sci. 885:287-311.

113. Sonkoly, E., et al. 2006. IL-31: a new link between $\mathrm{T}$ cells and pruritus in atopic skin inflammation. J. Allergy Clin. Immunol. 117:411-417.

114.Steinhoff, M., et al. 2003. Proteinase-activated receptor-2 mediates itch: a novel pathway for pruritus in human skin. J. Neurosci. 23:6176-6180.

115. Roosterman, D., Cottrell, G.S., Schmidlin, F., Steinhoff, M., and Bunnett, N.W. 2004. Recycling and resensitization of the neurokinin 1 receptor. Influence of agonist concentration and Rab GTPases. J. Biol. Chem. 279:30670-30679.

116.Stander, S., et al. 2003. Neurophysiology of pruritus: cutaneous elicitation of itch. Arch. Dermatol. 139: $1463-1470$

117. Blunk, J.A., et al. 2004. Opioid-induced mast cell activation and vascular responses is not mediated by mu-opioid receptors: an in vivo microdialysis study in human skin. Anesth. Analg. 98:364-370, table of contents.

118.Neisius, U., Olsson, R., Rukwied, R., Lischetzki, G., and Schmelz, M. 2002. Prostaglandin E2 induces vasodilation and pruritus, but no protein extravasation in atopic dermatitis and controls. J. Am. Acad. Dermatol. 47:28-32.

119.Yesudian, P.D., and Wilson, N.J. 2005. Efficacy of gabapentin in the management of pruritus of unknown origin. Arch. Dermatol. 141:1507-1509.

120.Horiuchi, Y., Bae, S., and Katayama, I. 2005. Nerve growth factor (NGF) and epidermal nerve fibers in atopic dermatitis model NC/Nga mice. J. Dermatol. Sci. 39:56-58

121.Ashida, Y., Denda, M., and Hirao, T. 2001. Histamine $\mathrm{H} 1$ and $\mathrm{H} 2$ receptor antagonists accelerate skin barrier repair and prevent epidermal hyperplasia induced by barrier disruption in a dry environment. J. Invest. Dermatol. 116:261-265.

122.Miyamoto, T., Nojima, H., Shinkado, T., Nakahashi, T., and Kuraishi, Y. 2002. Itch-associated response induced by experimental dry skin in mice. Jpn. J. Pharmacol. 88:285-292.

123.Peier, A.M., et al. 2002. A TRP channel that senses cold stimuli and menthol. Cell. 108:705-715.

124.Xu, H., et al. 2002. TRPV3 is a calcium-permeable temperature-sensitive cation channel. Nature. 418:181-186.

125. Brain, S.D. 2000. New feelings about the role of sensory nerves in inflammation. Nat. Med. 6:134-135. 